Open Access

\title{
Optimization of a multi-well colorimetric assay to determine haem species in Plasmodium falciparum in the presence of anti-malarials
}

Jill M. Combrinck', Kim Y. Fong ${ }^{2}$, Liezl Gibhard ${ }^{1}$, Peter J. Smith', David W. Wright ${ }^{2}$ and Timothy J. Egan ${ }^{3 *}$

\begin{abstract}
Background: The activity of several well-known anti-malarials, including chloroquine (CQ), is attributed to their ability to inhibit the formation of haemozoin $(\mathrm{Hz})$ in the malaria parasite. The formation of inert $\mathrm{Hz}$, or malaria pigment, from toxic haem acquired from the host red blood cell of the parasite during haemoglobin digestion represents a pathway essential for parasite survival. Inhibition of this critical pathway therefore remains a desirable target for novel anti-malarials. A recent publication described the results of a haem fractionation assay used to directly determine haemoglobin, free haem and $\mathrm{Hz}$ in Plasmodium falciparum inoculated with CQ. CQ was shown to cause a dose-dependent increase in cellular-free haem that was correlated with decreased parasite survival. The method provided valuable information but was limited due to its low throughput and high demand on parasite starting material. Here, this haem fractionation assay has been successfully adapted to a higher throughput method in 24-well plates, significantly reducing lead times and starting material volumes.
\end{abstract}

Methods: All major haem species in $P$. falciparum trophozoites, isolated through a series of cellular fractionation steps were determined spectrophotometrically in aqueous pyridine $(5 \% \mathrm{v} / \mathrm{v}, \mathrm{pH} 7.5)$ as a low spin complex with haematin. Cell counts were determined using a haemocytometer and a rapid novel fluorescent flow cytometry method.

Results: A higher throughput haem fractionation assay in 24-well plates, containing at most ten million trophozoites was validated against the original published method using CQ and its robustness was confirmed. It provided a minimum six-fold improvement in productivity and 24 -fold reduction in starting material volume. The assay was successfully applied to amodiaquine (AQ), which was shown to inhibit $\mathrm{Hz}$ formation, while the antifolate pyrimethamine (PYR) and the mitochondrial electron transporter inhibitor atovaquone (Atov) demonstrated no increase in toxic cellular free haem.

Conclusions: This higher throughput cellular haem fractionation assay can easily be applied to novel anti-malarials with a significantly decreased lead time, providing a valuable tool with which to probe the mechanisms of action of both new and established anti-malarials.

Keywords: Malaria, Plasmodium falciparum, Haem, Haemozoin, $\beta$-haematin, Colorimetry, 24-well plate assay, Flow cytometry

\footnotetext{
* Correspondence: Timothy.Egan@uct.ac.za

${ }^{3}$ Department of Chemistry, University of Cape Town, Private Bag,

Rondebosch 7701, South Africa

Full list of author information is available at the end of the article
}

\section{Biomed Central}

(c) 2015 Combrinck et al. This is an Open Access article distributed under the terms of the Creative Commons Attribution License (http://creativecommons.org/licenses/by/4.0), which permits unrestricted use, distribution, and reproduction in any medium, provided the original work is properly credited. The Creative Commons Public Domain Dedication waiver (http:// creativecommons.org/publicdomain/zero/1.0/) applies to the data made available in this article, unless otherwise stated. 


\section{Background}

The inhibition of the haem detoxification pathway in the malaria parasite, Plasmodium falciparum remains an attractive drug target with several important anti-malarials, primarily quinolines proposed to target it [1]. During its asexual erythrocytic cycle, free haem, derived from the digestion of host red blood cell haemoglobin (62 $\pm 13-\%)$ is autoxidized to poisonous haematin (Fe(III)PPIX), predominantly in the metabolically active trophozoite [2]. In an early study Ginsburg et al. detected an increase in membrane associated haem upon CQ and amodiaquine (AQ) treatment of cultured $P$. falciparum, but recovery of haemozoin in drug-free controls in this study was very low, with only $20-30 \%$ detected [3]. In a subsequent study it was shown that the overwhelming majority of this released haem (up to $95 \%$ ) is efficiently sequestered into inert crystalline haemozoin $(\mathrm{Hz})$ within the parasite's acidic digestive vacuole. Transmission electron microscopy (TEM) with electron energy loss spectroscopy (EELS) used to map the distribution of elemental Fe in mature trophozoite-infected erythrocytes (chloroquine (CQ) sensitive, D10 strain), confirmed $\mathrm{Hz}$ associated Fe is concentrated in the acidic digestive vacuole with very little Fe in the cytosol [2]. Hz formation has been shown to be closely associated with lipids [4]. Recently, neutral lipids associated with $\mathrm{Hz}$ were shown to mediate $\beta$-haematin $(\mathrm{BH}$, synthetic $\mathrm{Hz})$ formation under physiological conditions at rates analogous to parasite $\mathrm{Hz}$ formation [5]. This process of cellular lipid mediated $\mathrm{Hz}$ formation is mimicked synthetically in a detergent-mediated assay which substitutes neutral lipids for the lipophilic detergent NP40 [6]. This assay has been applied as a high throughput screening tool and identified several novel scaffolds capable of inhibiting $\mathrm{Hz}$ formation [7, 8]. The $\mathrm{Hz}$ inhibition pathway remains a favourable drug target despite resistance to known quinolines and related drugs which have been attributed to mutations in the parasite's 'chloroquine resistance transporter' (PfCRT) and other digestive vacuole membrane proteins [9]. In comparison to CQsensitive strains (CQS), resistant parasites have been shown to accumulate up to ten times less CQ in the digestive vacuole, falling outside the effective therapeutic range for $\mathrm{CQ}$ [10]. The formation of $\mathrm{Hz}$ is unaffected by PfCRT mutations and so $\mathrm{Hz}$ inhibitors remain one of the most successful classes of anti-malarials to date.

The use of detergent-based screening methods as a synthetic measure of the ability of a compound to inhibit the formation of $\mathrm{BH}$ is routinely used to identify $\mathrm{BH}$ inhibitors $[8,11]$. This method has been translated into an analogous process in malaria parasites cultured in vitro, the haem fractionation assay, a method capable of directly measuring haem species in CQS P. falciparum [12]. Originally applied to $\mathrm{CQ}$, this cellular fractionation technique colorimetrically measures haem as $\mathrm{Fe}(\mathrm{III})$ haem-pyridine complex based on a previously published method by Ncokazi and Egan in which it was shown that in a mixture of $\mathrm{BH}$ and haematin, the latter forms a low-spin complex with aqueous pyridine ( $5 \% \mathrm{v} / \mathrm{v}, \mathrm{pH} 7.5$ ) without disturbing $\mathrm{BH}$ [13]. Using the cellular haem fractionation assay, CQ was shown to cause a dose-dependent increase in 'free' haem (i.e., labile haem that can be solubilized with detergent), along with a decrease in $\mathrm{Hz}$ correlated to the survival of P. falciparum cells. TEM with EELS of CQ-treated cells showed a redistribution of Fe from the digestive vacuole into the parasite cytoplasm [12]. The method provided valuable information, successfully demonstrating the ability of CQ to inhibit cellular $\mathrm{Hz}$ formation. Due to its protracted nature, however, it could not easily be extended to other drugs. Here, a modified technique designed to increase output and reduce material costs is described in detail. Performed in 24-well plates, multiple drug concentrations can be evaluated in one session with relatively low amounts of parasite starting material. At minimum results can be obtained for two compounds per week, a significant improvement in output over the previous method, which produced results for one compound every 2 months. The method was successfully validated against the original haem fractionation assay performed in flasks using CQ. This validated method was applied to three clinically relevant anti-malarials covering a broad spectrum of mechanisms of actions: the 4-aminoquinoline AQ which like CQ has been shown to inhibit BH formation, the non- $\mathrm{BH}$ inhibiting antifolate pyrimethamine (PYR) [7] and finally the non-BH inhibiting anti-malarial atovaquone (Atov). While initial results for Atov showed an unanticipated increase in the percentage of free haem with increasing Atov concentration, the total amount of haem iron per cell was found to be significantly less in cells treated with Atov. This corresponds to unchanged free haem per cell with increasing Atov concentration. This example with Atov demonstrates the importance of establishing the total amount of haem iron per cell, a calculation which requires the determination of the cell count in each well of the 24-well plate. Cell counts were determined using a haemocytometer and flow cytometry based method with fluorescent cell staining [14-19]. Acquiring cell counts for a large number of samples with a haemocytometer proved a tedious process, as a result counting was also performed with a novel flow cytometry method using SYBR green I fluorescent staining of isolated cells. Over the course of the $48 \mathrm{~h}$ lifecycle of the parasite the amount of DNA increases as the parasite matures from early rings to multi-nucleated schizonts, translating to an increase in the SYBR green I fluorescence signal as a result of binding to double stranded parasite DNA [19]. SYBR green I was specifically chosen due to its low binding affinity for RNA and preference for double stranded DNA over single stranded DNA [20]. In addition 
to relieving the burden of manual cell counting, this flow cytometry method can also provide important information about morphological changes in the presence of cells treated with anti-malarials.

The method described here is a modified version of an established technique which details the increased output of a previously published assay allowing for the determination of haem species spectroscopically in isolated $P$. falciparum trophozoites.

\section{Methods}

Unless otherwise stated, all materials used were obtained from Sigma Life Sciences.

\section{In vitro culture of Plasmodium falciparum parasites}

A CQS strain of P. falciparum, D10, was used throughout this study and cultured using a modified method of Trager and Jensen [21]. Briefly, parasites were maintained in fresh type $\mathrm{O}+$ human erythrocytes in medium containing 10.4 g/l RPMI 1640 with glutamine (and without $\mathrm{NaHCO}_{3}$ ), $4 \mathrm{~g} / \mathrm{l}$ glucose, $6 \mathrm{~g} / \mathrm{l}$ HEPES, $0.088 \mathrm{~g} / \mathrm{l}$ hypoxanthine, $1.2 \mathrm{ml} / \mathrm{l}$ gentamycin and $5 \mathrm{~g} / \mathrm{l}$ Albumax II (GIBCO). Directly before use, $8.4 \mathrm{ml}$ of $5 \%(\mathrm{w} / \mathrm{v})$ $\mathrm{NaHCO}_{3}$ was added to $200 \mathrm{ml}$ medium. Cultures were kept at $37{ }^{\circ} \mathrm{C}$ in $200-\mathrm{ml}$ flat-bottom flasks under a gas environment of $3 \% \mathrm{O}_{2}, 4 \% \mathrm{CO}_{2}$, and $\mathrm{N}_{2}$. The integrity of the culture was monitored daily using $10 \%(\mathrm{v} / \mathrm{v})$ Giemsa (Merck) stained slides. Synchronization was maintained by treating with five volumes of $5 \%(\mathrm{w} / \mathrm{v})$ sorbitol for $10 \mathrm{~min}$ on ring days. Post synchronisation, cultures were centrifuged at $750 \mathrm{rcf}$ for $5 \mathrm{~min}$ and the layer of debris corresponding to lysed cells and the associated $\mathrm{Hz}$ was carefully removed from the culture by aspiration.

\section{Biological $\mathrm{IC}_{50}$ determination}

In vitro antiplasmodial activity was determined via the parasite lactate dehydrogenase assay using a modified method described by Makler et al., which colorimetrically measures Plasmodium lactate dehydrogenase [22]. Test samples were prepared to a $20 \mathrm{mg} / \mathrm{ml}$ stock solution in $100 \%$ dimethyl sulfoxide (DMSO, Merck) and stored at $-20{ }^{\circ} \mathrm{C}$. On the day of use, samples were diluted in medium to a starting concentration of $100 \mu \mathrm{g} / \mathrm{ml}$ and serially diluted two-fold in medium in 96-well plates. All samples were tested in triplicate at ten concentrations, with the lowest concentration being $0.2 \mu \mathrm{g} / \mathrm{ml}$. The highest concentration of DMSO to which the parasites were exposed was $0.5 \%(\mathrm{v} / \mathrm{v})$. The $\mathrm{IC}_{50}$-values were obtained using a non-linear doseresponse curve fitting analysis via Graph Pad Prism v.4.0 software [23].

\section{Haem fractionation assay}

\section{Incubation and harvesting}

Aliquots of $2 \mathrm{ml}$ of early ring-stage sorbitol synchronized parasites at $5 \%$ parasitaemia and $2 \%$ haematocrit were added to each well of a 24-well flat-bottom cell culture plate (Greiner Bio-One). All test compounds were diluted in medium from the previously prepared $20 \mathrm{mg} /$ $\mathrm{ml}$ stock solution and added to the plate such that the final volume per well was $2020 \mu \mathrm{l}$ and the final concentrations tested were at several multiples of the compound's $\mathrm{IC}_{50}$-value. Each concentration was tested as four replicates and the highest concentration of drug tested was at $4 \times \mathrm{IC}_{50}$, since beyond this concentration very few cells remained for harvesting. Plates were incubated at $37{ }^{\circ} \mathrm{C}$ in a gas chamber with $3 \% \mathrm{O}_{2}, 4 \% \mathrm{CO}_{2}$, and $\mathrm{N}_{2}$. After $32 \mathrm{~h}$, excess supernatant was aspirated and Giemsa-stained thin smears were prepared on glass slides at each concentration tested. Each pellet was resuspended in $1.9 \mathrm{ml}$ phosphate buffered saline (PBS) $\mathrm{pH} 7.5$ and transferred to a deep well $2.2 \mathrm{ml}$ rectangular 96-well plate (Labcon). The new plates ensured maximum sample recovery in subsequent steps and were essential for further processing. Erythrocytes were lysed with the addition of $100 \mu \mathrm{l} 1 \%(\mathrm{w} / \mathrm{v})$ saponin. After $2 \mathrm{~min}$ at $37{ }^{\circ} \mathrm{C}$ plates were centrifuged at $750 \mathrm{rcf}$ for $15 \mathrm{~min}$. The supernatant was aspirated and the pellets washed three times with $0.5 \mathrm{ml}$ PBS to remove all traces of erythrocyte haemoglobin $(\mathrm{Hb})$. The washed pellet, corresponding primarily to isolated trophozoites, was resuspended, diluted to a final volume of $100 \mu$ l with PBS $\mathrm{pH} 7.5$ and accurately transferred to a round-bottomed, 96-well $0.5 \mathrm{ml}$ plate (Axygen Scientific) referred to as the stock plate. The stock plate was used to prepare a second plate for cell counting after which it was frozen at $-80{ }^{\circ} \mathrm{C}$.

\section{Preparation of the counting plate and cell fixation}

A counting plate was prepared by adding $10 \mu \mathrm{l}$ of the isolated washed trophozoites to the corresponding wells of a flat-bottomed 96-well plate. The cells were fixed with $0.125 \%$ (v/v) glutaraldehyde in PBS pH 7.5 to a final volume of $200 \mu \mathrm{l}$ and refrigerated at $4{ }^{\circ} \mathrm{C}$ overnight.

\section{Haemocytometer counting}

Haemocytometer counting was performed on the first row of each plate only, corresponding to six samples, each at a different concentration of the drug tested. The haemocytometer determined cell counts for these six samples were statistically compared to the cell counts determined by flow cytometry to test for agreement. Ten $\mu \mathrm{l}$ of cells from the counting plate were loaded onto a bright-line haemocytometer and five large squares were counted after 10 min of settling. The concentration of 
cells in each well of the plate was determined using equation 1 :

$$
C_{H}=N \times F \times D F \times 10,000
$$

Where:

$C_{H}=$ concentration of cells per $\mathrm{ml}$ as determined with haemocytometer

$N=$ number of cells counted in five fields

$F=$ number of fields counted $=5$

$D F=$ dilution factor

\section{Flow cytometry counting}

Cell counts for all samples on the counting plate were determined using flow cytometry [14, 16, 17]. Samples were analysed on a Becton Dickinson FACSCalibur using SSC/FL1 $1_{530 \mathrm{~nm}}$ with CellQuestPro software. Typically 10,000 events were counted for each sample. Samples were prepared by diluting $100 \mu \mathrm{l}$ of cells from the counting plate with $800 \mu \mathrm{l}$ of $1 \times \mathrm{SYBR}^{\circ}$ green I in $\mathrm{PBS} \mathrm{pH} 7.5$ and incubating for $30 \mathrm{~min}$ in the dark at $37{ }^{\circ} \mathrm{C}$. Next, each sample was spiked with $100 \mu \mathrm{l}$ of Trucount ${ }^{\text {tix }}$ beads (Becton Dickinson) such that each sample contained a known fixed amount of fluorescent beads in a final volume of $1 \mathrm{ml}$ and was mixed well. The concentration of cells in the acquisition tube was calculated according to equation 2:

$$
C_{F}=(T / B) \times C_{B}
$$

Where:

$C_{F}=$ concentration of cells per $\mathrm{ml}$ as determined with flow cytometry

$\mathrm{T}=$ number of trophozoites gated

$B=$ number of fluorescent beads gated
$C_{B}=$ concentration of fluorescent beads in the acquisition tube per $\mathrm{ml}$ (calibrated bead count per acquisition is unique to each lot of tubes obtained from the supplier)

Trophozoite gates were established by running isolated trophozoites obtained from a highly synchronous trophozoite culture through the process of harvesting and flow cytometry analysis as described above. The resulting dot plot in Fig. 1a represents a population corresponding to primarily trophozoites. The presence of trophozoites was confirmed with a $10 \%(\mathrm{v} / \mathrm{v})$ Giemsa-stained slide. The same process was applied to a highly synchronous ring culture and the resulting dot plot of cell material accrued as a consequence of the harvesting process (most likely corresponding to both rings and cell debris) can be seen in Fig. 1b. A $10 \%(\mathrm{v} / \mathrm{v})$ Giemsa-stained slide confirmed the presence of accumulated cell debris; however it was difficult to distinguish rings from the debris. The trophozoite population corresponds to cells of a much higher fluorescent intensity and side scatter (SSC) indicating more complex cells with more nucleic acid in comparison to the population of rings and debris with lower fluorescent intensity and SSC. The latter population was omitted during gating and only intact trophozoites were gated and used to determine cell counts. The population of cells corresponding to Fig. 1a and $\mathrm{b}$ were assayed for haem as described below in the haem fraction assay. Initial gating was performed with unstained cells to account for autofluorescence. All samples were analysed using FloJo software version 10 (Tree Star Inc).

\section{Haem fractionation}

After thawing the stock plate, $50 \mu \mathrm{l}$ of water was added and the plate was sonicated for $5 \mathrm{~min}$ in an ultrasound
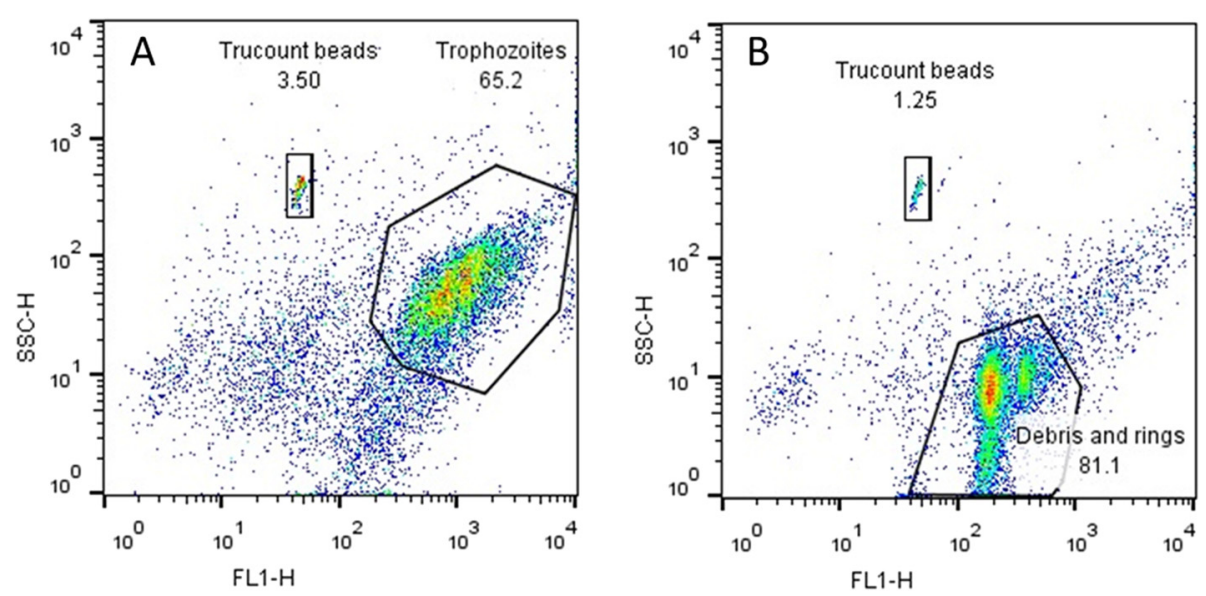

Fig. 1 Dot plots displaying isolated Plasmodium falciparum cells corresponding to trophozoites (a) and rings and cell debris (b) after staining with the fluorescent DNA dye, SYBR green I and the populations corresponding to fluorescent Trucount beads 
bath $(53 \mathrm{kHz}, 320 \mathrm{~W}$, Bandelin Sonerex). This was followed by the addition of $50 \mu \mathrm{l}$ each of $0.2 \mathrm{M}$ HEPES buffer $\mathrm{pH} 7.5$ and water. The plate was then centrifuged at $3600 \mathrm{rpm}$ for $20 \mathrm{~min}$. Very carefully, without disturbing the pellet, the supernatant was transferred to an adjacent set of wells on the same plate. The supernatant was processed further with $50 \mu \mathrm{l} 4 \%$ SDS, sonicated for $5 \mathrm{~min}$ and then incubated at $37{ }^{\circ} \mathrm{C}$ for $30 \mathrm{~min}$. Fifty $\mu \mathrm{l}$ of $0.3 \mathrm{M} \mathrm{NaCl}$ and $50 \mu \mathrm{l}$ of $25 \%$ (v/v) pyridine in $0.2 \mathrm{M}$ HEPES $\mathrm{pH} 7.5$ were added and $200 \mu \mathrm{l}$ of the solution was transferred to a flatbottomed UV-Star 96-well plate. This fraction corresponds to the $\mathrm{Hb}$ fraction.

The pellet was treated with $50 \mu \mathrm{l}$ water, $50 \mu \mathrm{l} 4 \%$ SDS and resuspended. The plate was sonicated for $5 \mathrm{~min}$ and incubated at $37{ }^{\circ} \mathrm{C}$ for $30 \mathrm{~min}$ to solubilize free haem. This was followed by the addition of $50 \mu \mathrm{l} 0.2 \mathrm{M}$ HEPES $\mathrm{pH} 7.5,50 \mu \mathrm{l} 0.3 \mathrm{M} \mathrm{NaCl}$ and $50 \mu \mathrm{l} 25 \%$ pyridine. The plate was centrifuged at $3700 \mathrm{rpm}$ for $20 \mathrm{~min}$. Very carefully without disturbing the pellet, the supernatant was transferred to an adjacent set of wells on the same plate. The supernatant was diluted to a final volume of $400 \mu \mathrm{l}$ with water. This fraction corresponds to the free haem fraction; $200 \mu \mathrm{l}$ of this solution was transferred to the flat-bottomed UV-Star 96-well plate, the same plate previously used for the $\mathrm{Hb}$ fraction.

The remaining pellet containing $\mathrm{Hz}$ was solubilized in $50 \mu \mathrm{l}$ of water and $50 \mu \mathrm{l} 0.3 \mathrm{M} \mathrm{NaOH}$. The plate was sonicated for $15 \mathrm{~min}$ and incubated at $37^{\circ} \mathrm{C}$ for $30 \mathrm{~min}$ and $50 \mu \mathrm{l}$ each of 0.2 M HEPES $\mathrm{pH} 7.5,0.3 \mathrm{M} \mathrm{HCl}$ and $25 \%$ pyridine was added followed by $150 \mu \mathrm{l}$ water. This fraction corresponds to the $\mathrm{Hz}$ fraction; $200 \mu \mathrm{l}$ of this solution was transferred to vacant wells in the flatbottomed UV-Star 96-well plate containing the $\mathrm{Hb}$ and free haem fractions. The UV-visible spectra of haem as $\mathrm{Fe}(\mathrm{III})$ haem-pyridine complex was recorded using a multi-well plate reader (Spectramax 340PC, Molecular Devices). The absorbance maxima of the Fe(III)haem pyridine complex in each well was used to calculate the percentage of each haem species in each sample as the final volume for each fraction was identical. The procedure is presented graphically in Fig. 2.

\section{Haem standard curve}

The total amount of haem in each fraction was quantified using a haem standard curve prepared from a

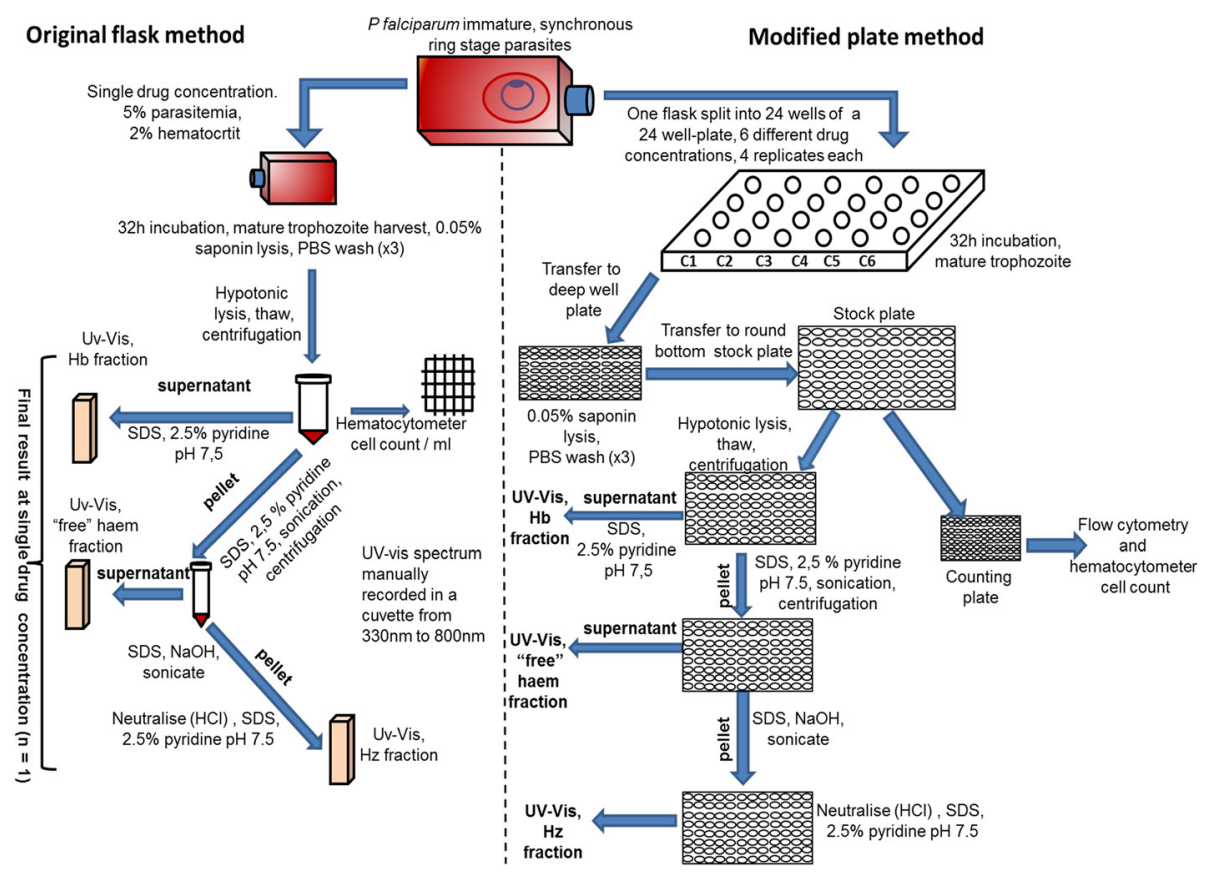

Fig. 2 Flow diagram showing the haem fractionation assay: original flask method (left) versus increased throughput plate method (right). The haem fractionation assay is a cellular fractionation technique based on the ability of neutral aqueous pyridine to selectively form a low spin haem-pyridine complex with free haem in the presence of $\mathrm{Hz}$ [13]. The original method was performed in $250 \mathrm{ml}$ culture flasks, testing a single drug concentration at a time and performing spectroscopic measurements in a cuvette [12]. The modified method was performed in 24-well plates, testing several drug concentrations, four replicates at a time and using a multiwell plate reader to record absorbance, resulting in a six-fold increase in output. Immature ring stage parasitized red blood cells were inoculated with several different increasing drug concentrations. After $32 \mathrm{~h}$, mature trophozoites were harvested via saponin lysis of erythrocytes. Following hypotonic lysis and centrifugation, SDS treated soluble Hb was measured in the supernatant as a low spin haem-pyridine complex. The pellet was further treated with SDS and pyridine to solubilize free haem, measured in the supernatant following centrifugation. $\mathrm{Hz}$ was measured after solubilizing the pellet in $\mathrm{NaOH}$, neutralizing with $\mathrm{HCl}$ and treating with pyridine 
$100 \mu \mathrm{g} / \mathrm{ml}$ haem standard solution of haematin (porcine) in $0.3 \mathrm{M} \mathrm{NaOH}$. Serial dilutions of the standard were carried out in a 96-well plate with $100 \mu \mathrm{l} 0.3 \mathrm{M} \mathrm{NaOH}$ as a blank. Fifty $\mu$ l of each of the following solutions were added to $100 \mu \mathrm{l}$ of haematin standard: $0.2 \mathrm{M}$ HEPES pH 7.5, 4 \% (w/v) SDS, $0.3 \mathrm{M} \mathrm{NaCl}, 0.3 \mathrm{M} \mathrm{HCl}$, $25 \%$ pyridine in $0.2 \mathrm{M}$ HEPES $\mathrm{pH} 7.5$ and water. The visible spectra of haem as Fe(III)haem-pyridine complex were recorded in a multi-well plate reader. The amount of haem Fe per cell was calculated by dividing the total haem $\mathrm{Fe}$ in each fraction by the number of cells determined in each fraction.

\section{Statistical analysis}

Bland Altman analysis was used to assess the agreement between the original haem fractionation method and modified plate method [24]. For determination of statistical significance of differences in measurements relative to controls, a two-tailed $t$-test ( $95 \% \mathrm{CI}$ ) was used and is displayed on graphs using asterisks ( ${ }^{*} \mathrm{P}<0.05$; ${ }^{* *} \mathrm{P}<0.01$; *:* $\mathrm{P}<0.001)$. In all cases data represent a minimum of three repeats. All analysis was carried out using GraphPad Prism version 4.0 software [23].

\section{Results and discussion}

\section{Cell counting: haemocytometer versus flow cytometer}

Cell counts, required for the determination of the total amount of haem Fe per cell (reported in fg/cell) were originally determined manually using a haemocytometer. This method was found to be slow and tedious when applied to 24 samples per plate and an alternative, more efficient method for counting cells was set up using flow cytometry. Post fixation with glutaraldehyde, cells were stained with the DNA binding fluorescent dye SYBR green I, spiked with a fixed number of fluorescent Trucount $^{\text {tw }}$ beads (Becton Dickinson) and analysed with a Becton Dickinson FACS Calibur using SSC/FL1 $1_{530 n m}$

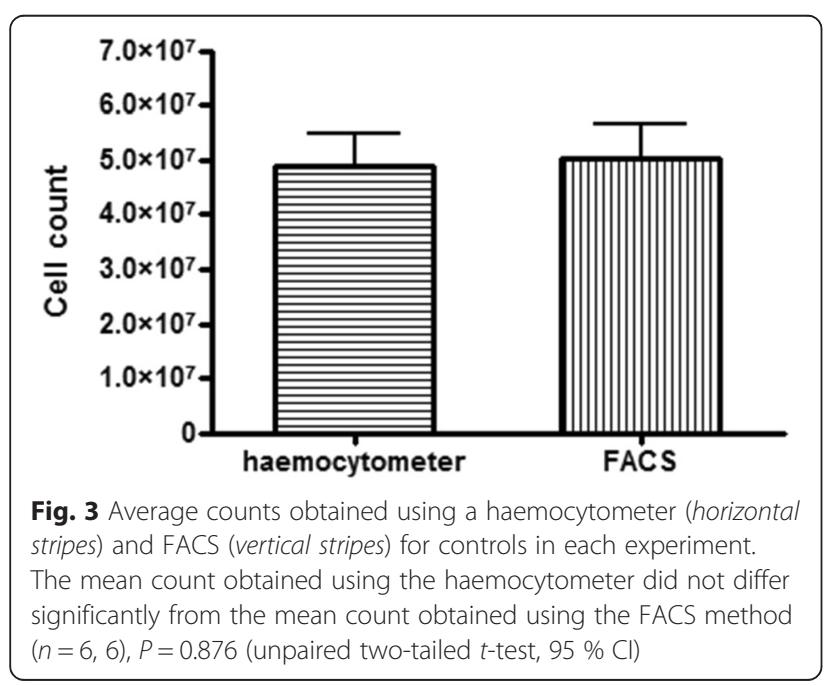

Table 1 Summary of P-values (unpaired 2-tailed t-test, $95 \% \mathrm{Cl}$ ) obtained when comparing the counts obtained with the FACS method to the haemocytometer method at each concentration of each drug tested

\begin{tabular}{llclcccl}
\hline CQ $(\mathrm{nM})$ & $P$ & $\mathrm{AQ}(\mathrm{nM})$ & $P$ & Atov $(\mathrm{nM})$ & $P$ & PYR $(\mathrm{nM})$ & $P$ \\
\hline 7.5 & 0.92 & 12.5 & 0.12 & 1 & 0.75 & 25 & 0.13 \\
15 & 0.68 & 25 & 0.56 & 2 & 0.92 & 50 & 0.12 \\
30 & 0.32 & 50 & 0.056 & 4 & 0.69 & 100 & 0.087 \\
45 & 0.89 & 75 & 0.28 & 8 & 0.83 & 150 & 0.11 \\
90 & 0.96 & 100 & 0.061 & 16 & 0.23 & 200 & 0.86 \\
\hline
\end{tabular}

In all cases the mean count obtained using the haemocytometer did not differ significantly from the mean count obtained using the FACS method

with CellQuestPro software. Cell counts using flow cytometry were performed on all wells of each 24-well plate and haemocytometer counts were routinely done on the first row only of each 24-well plate for comparison and to establish agreement between the methods. In both cases only intact isolated trophozoites were counted. Flow cytometry is a faster, less subjective process than haemocytometer counting but is not without limitations. The first issue relates to the accurate gating of cells. Despite having established a gate specifically for trophozoites (Fig. 1a) which excludes any rings and cell debris collected during the process of harvesting (Fig. 1b), an overlap exists where cells which appear as larger, mature rings have the same SSC and fluorescent intensity as immature or underdeveloped trophozoites and it is not possible to distinguish the two, which can result in an inaccurate trophozoite cell count. The second issue is counting aggregates of cells as a single complex cell resulting in undercounting, however this is largely overcome by mixing samples well during

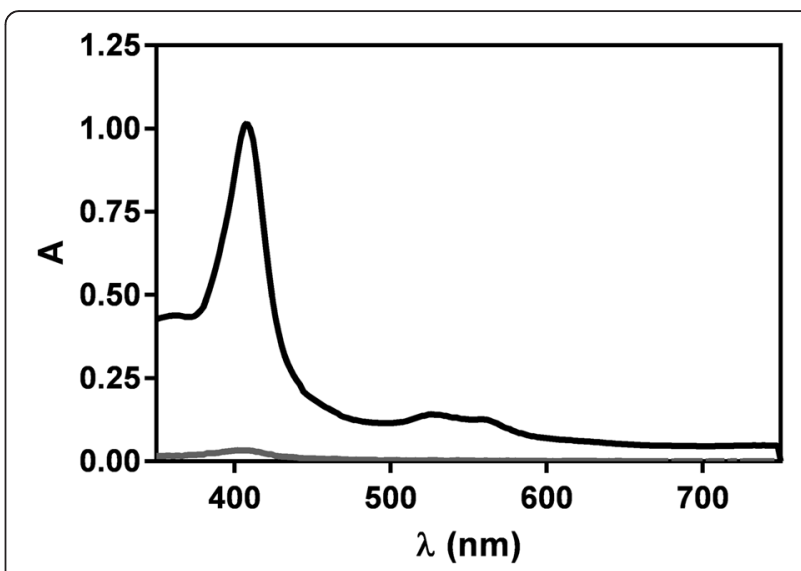

Fig. 4 Absorbance spectra of $\mathrm{Hz}$ haem for the ring (gray) and trophozoite (black) stages obtained from the same culture. The Soret peak obtained from the ring stage is very weak compared to that from the trophozoite stage. The maximum content of haemozoin in the ring culture is $4.2 \pm 0.4 \%(n=4)$ of that in the trophozoites. In order to detect a significant signal from the ring stage, these experiments were conducted with $2.5 \times 10^{7}$ parasites 

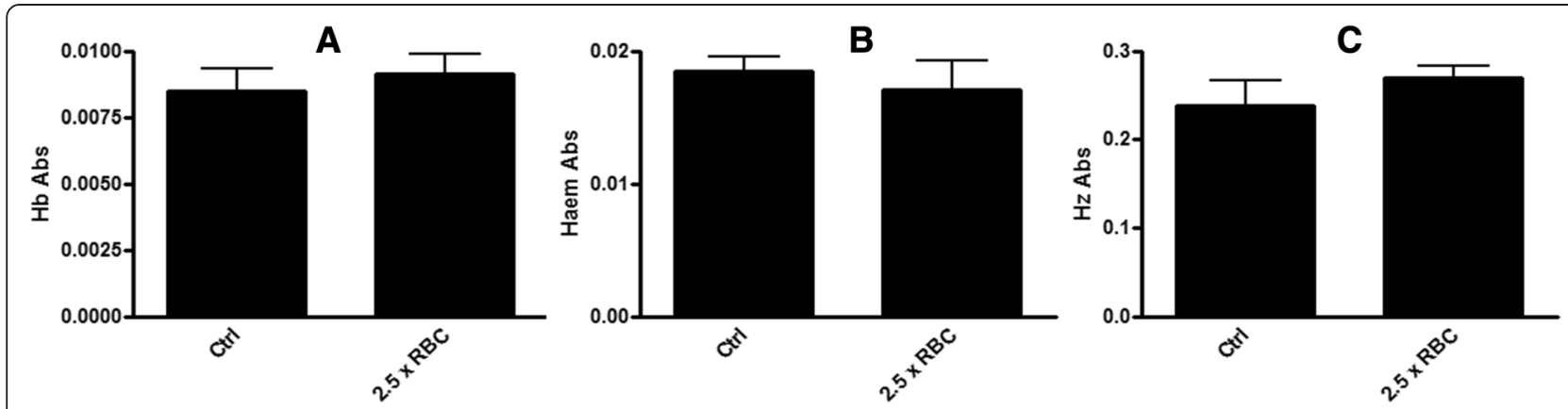

Fig. 5 The Soret band absorbance readings for $\mathrm{Hb}(\mathbf{a})$, haem (b) and $\mathrm{Hz}$ (c) fractions of a sample spiked with $100 \mu \mathrm{ll}$ of RBCs compared to a control sample containing $40 \mu \mathrm{l}$ of $5 \%$ parasitized RBCs under identical conditions. No significant change was seen in the haem levels of the Hb fraction $(P=0.57)$, the haem fraction $(P=0.52)$ or the $\mathrm{Hz}$ fraction $(P=0.33)$ of the sample spiked with 2.5 fold more RBCs than the control (unpaired two-tailed t-test, $95 \% \mathrm{Cl}, n=6$ ). Both the control and spiked sample contained $10^{7}$ parasites and were from the same culture

preparation and running the samples at a low flow rate. Despite the limitations associated with both counting methods, it was found there was no statistical difference between the means as determined by each counting method (unpaired two-tailed $t$-test, $95 \% \mathrm{CI}$ ) for the untreated control (Fig. 3). Furthermore, no significant difference was seen at any concentration of the four drugs tested (Table 1).

\section{Assessment of the robustness of the assay}

In the previous report on the flask method for determination of haem species in $P$. falciparum, the method was not described in detail [12]. In particular, the specificity of the assay for different haem species in the various fractions was not investigated with respect to crosscontamination at each of the fractionation steps. This has now been addressed in the plate assay.

When cultured parasites are synchronized with sorbitol, trophozoites present in the asynchronous culture are lysed and release their haemozoin. If no precautions were taken, this haemozoin would be carried into the synchronized culture used in the assay. To avoid this, visible pigmented cell debris was removed by aspiration immediately following sorbitolization. To confirm that significant quantities of pre-formed haemozoin did not contaminate the sample, a synchronous culture was subjected to the process of harvesting, followed by the haem fractionation assay at the ring stage soon after sorbitol treatment. At this stage of the lifecycle, early rings would have produced no haemozoin. Consequently, any haem detected in the haemozoin fraction arises from either haemozoin carried over during synchronization, or from a small fraction of trophozoites that survive sorbitol treatment. Figure 4 shows that the absorbance spectrum of haem present in this fraction was very low compared to material isolated from the same culture at the trophozoite stage. The cross contamination from previous cycles was thus at most $4 \%$ (since a portion of the small absorbance seen almost certainly arose from trophozoites still present in the culture post synchronization). Thus, the carry-over of $\mathrm{Hz}$ from previous cycles was found to be negligible.

A second potential source of cross-contamination is $\mathrm{RBC} \mathrm{Hb}$, which is the dominant form of haem in the total culture at $5 \%$ parasitaemia. Trophozoites isolated by saponin lysis are accompanied by lysed RBC membranes. The pellet could be contaminated with $\mathrm{Hb}$ if the washing steps are not efficient enough to remove it and would result in elevated trophozoite $\mathrm{Hb}$ readings. The elevated readings could potentially carry over into subsequent fractions. To test this, the $40 \mu \mathrm{l}$ RBC pellet containing $5 \%$ parasitized cells was spiked with $100 \mu \mathrm{L}$ of packed RBCs. This mixture was then subjected to the usual harvesting and haem fractionation assay and all the haem species were measured. As shown in Fig. 5, none of the fractions showed any significant change in haem levels relative to the unspiked control. This demonstrated that cross-contamination by $\mathrm{RBC} \mathrm{Hb}$ is not significant provided that the washing protocol is followed.

Finally, the 'free' haem fraction could potentially be contaminated as a result of the breakdown of haemozoin during ultrasound treatment in the presence of SDS. Two approaches were used to test this. Firstly, the duration of ultrasound treatment was increased three-fold to $15 \mathrm{~min}$. No significant change in free haem levels was detected (Table 2). Secondly, the pellet containing 'free'

Table 2 Summary of mean absorbances $(n=6)$ and $P$-values (unpaired 2-tailed t-test, $95 \% \mathrm{Cl}$ ) for the control, a sample sonicated for $15 \mathrm{~min}$ and a sample spiked with $\mathrm{Hz}$

\begin{tabular}{lcc}
\hline Sample & Average absorbance & $P$-value \\
\hline Control & $0.024 \pm 0.003$ & $\mathrm{~N} / \mathrm{A}$ \\
Sonicated for 15 min & $0.021 \pm 0.001$ & 0.08 \\
$\mathrm{~Hz}$ Spiked & $0.027 \pm 0.006$ & 0.26 \\
\hline
\end{tabular}


haem and haemozoin was spiked with isolated haemozoin prior to addition of SDS and ultrasound treatment. The haemozoin was obtained from the final pellet of a control experiment isolated prior to addition of $\mathrm{NaOH}$ and doubled the quantity of haemozoin in the sample. Isolation of 'free' haem from this spiked sample showed no significant difference relative to an unspiked control (Table 2). This confirmed that haemozoin does not contaminate the 'free' haem fraction.
Validation of plate method with $\mathrm{CQ}$

The plate method was validated in CQS D10 P. falciparum inoculated with $\mathrm{CQ}$, since a full dose response profile was previously reported for CQ using the flask method at several different concentrations [12], allowing for direct comparison of results. The effect on all three haem species was examined and statistically compared to the previously published data obtained with the original flask method (Fig. 6a, b, c, and g) [12].

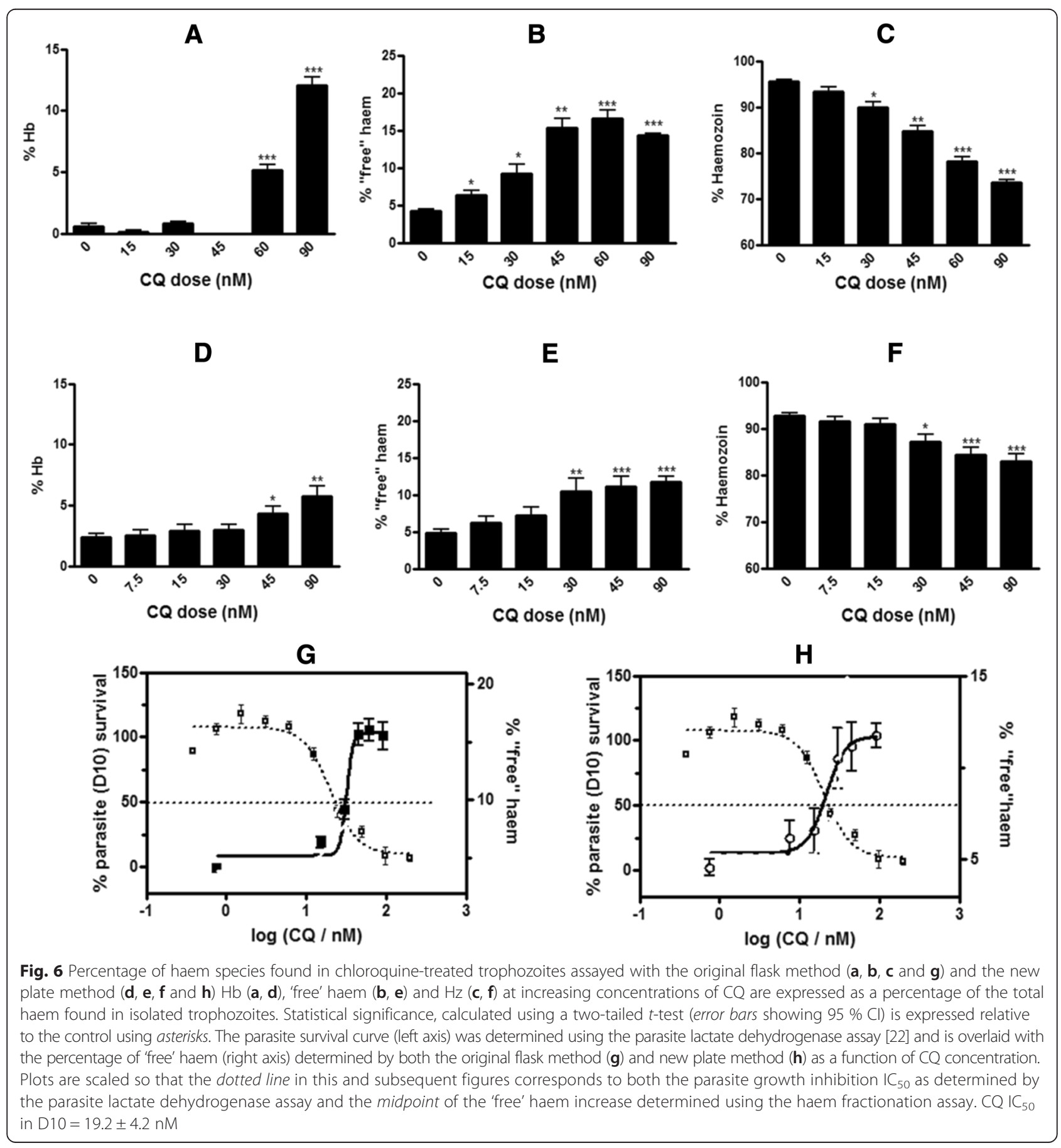


Both methods showed a dose dependent increase in percentage 'free' haem with corresponding decrease in $\mathrm{Hz}$ in CQS P. falciparum inoculated with CQ (Fig. 6b, c, e and $f)$. In both cases the rise in 'free' haem mirrors the decline in the survival curve of the parasite such that at higher concentrations of 'free' haem corresponding to parasites exposed to high doses of CQ very few trophozoites survive after the 32-h incubation period (Fig. 5g, h). Although the trend for both methods is the same, the modified plate method showed a more muted response for both the increase in 'free' haem and decrease in $\mathrm{Hz}$ (Fig. 6b, c, e and f). In the flask method, the maximum increase in 'free' haem was $10.2 \%$ compared to the control, while in the plate method the maximum increase in 'free' haem compared to the control was $7.0 \%$. This is probably attributable to the decreased absorbance as a result of reduced starting material volumes for each sample, which is in turn associated with larger errors. Small but significant sample losses which occur at each fractionation step, as well as sample carry over during the transfer and separation of the supernatant and pellets are also likely contributory factors.
Bland Altman analysis was used to statistically compare the two methods with respect to the percentage of each haem species calculated [24]. For each haem species the difference in the average of the result obtained with the flask and modified plate method was plotted against the mean of the result obtained with each method. The agreement between the two methods for both 'free' haem (Fig. 7b) and $\mathrm{Hz}$ (Fig. 7c) were good, showing narrow limits of agreement in comparison to the means. Hz however does show evidence of systematic error for the three lowest mean percentages, corresponding to cells which were dosed at $90 \mathrm{nM} C Q$ (greater than four times the $\mathrm{IC}_{50}$ of CQ). This is most likely associated with larger errors due to poor recovery at high drug concentrations. $\mathrm{Hb}$ (Fig. 7a) showed much broader limits of agreement between the methods relative to the mean for each set of measurements. The determination of $\mathrm{Hb}$, specifically in the plate method was very often associated with large errors owing to the small sample volume used, resulting in low absorbance values for $\mathrm{Hb}$, which is present in very small amounts in mature trophozoites. In view of the good agreement for $\mathrm{Hz}$ and especially 'free' haem, the higher

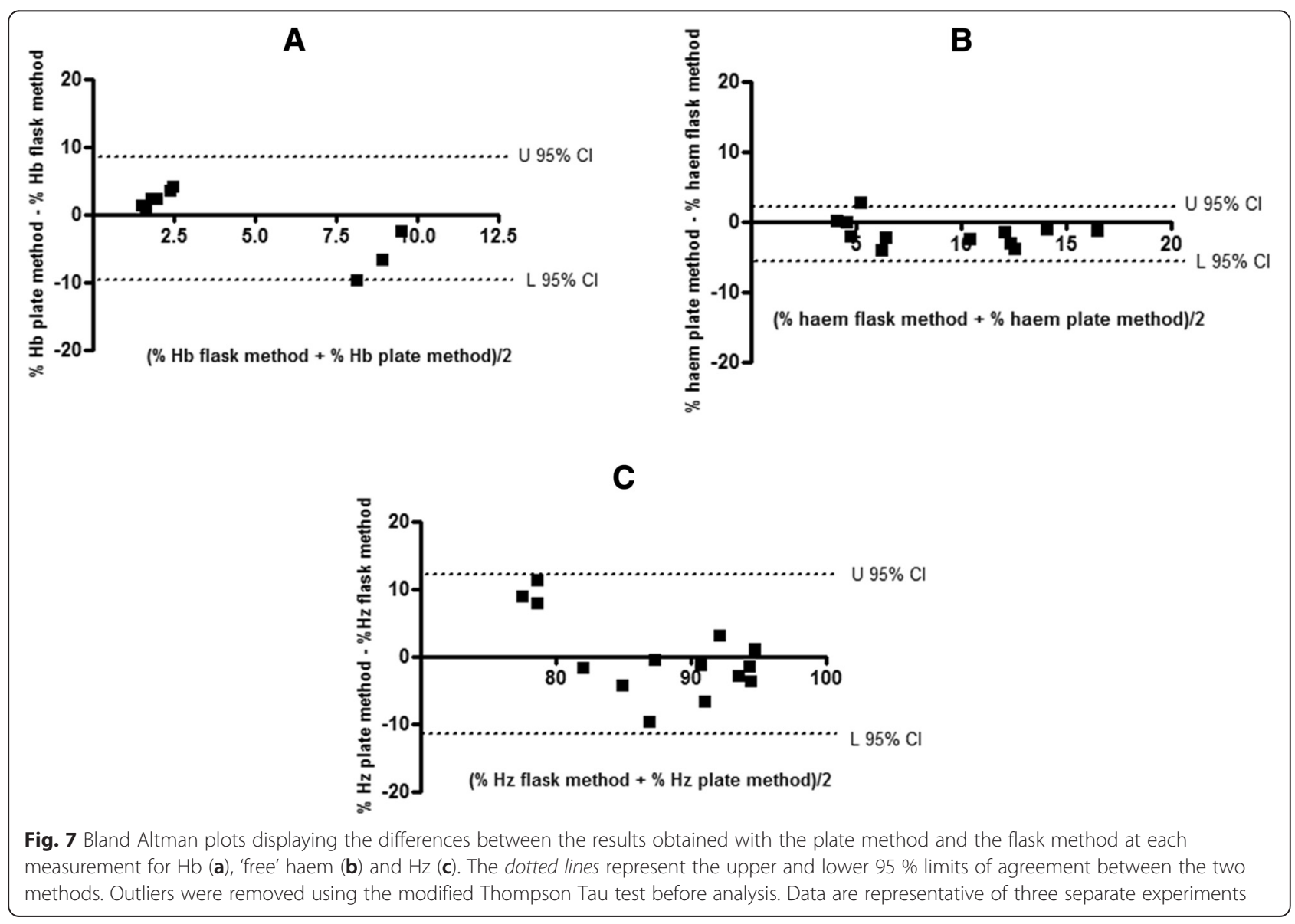


throughput plate method was subsequently used for further investigations of its versatility.

Cell counts determined by flow cytometry were used to determine the amount of haem Fe per trophozoite (fg/cell) at each dose of CQ. Previous studies on trophozoites isolated using the older flask method with haemocytometer cell counting showed that the total amount of haem Fe in CQ-treated cells was not statistically different to control cells [12]. These results were confirmed in the current study where it was found that the total haem Fe in CQ-treated trophozoite cells was statistically indistinguishable from control cells (Fig. 8d). The haem fractionation profiles showing the amount of $\mathrm{Hb}$ (Fig. 8a), 'free' haem (Fig. 8b) and Hz (Fig. 8c) Fe per trophozoite with increasing $C Q$ concentration followed the same trend as the corresponding percentage profiles seen in Fig. $6 \mathrm{~d}$, e and f. Similarly an overlay of the parasite survival curve with the amount of 'free' haem Fe per trophozoite shows an increase in the amount of 'free' haem per cell correlated to cell death (Fig. 8e) with both graphs intersecting at a point corresponding to $50 \%$ parasite survival.

\section{Amodiaquine}

The new method was applied to another 4-aminoquinoline, $A Q$, which like $C Q$ has also been shown to inhibit $B H$ formation with the NP-40 detergent mediated $\mathrm{BH}$ inhibition assay [7]. Preliminary results for 'free' haem performed on parasites treated with $\mathrm{AQ}$ at $2.5 \times$ the parasite growth inhibition $\mathrm{IC}_{50}$ showed an increase in 'free' haem significantly different to the control [12]. A full dose response carried out using the plate method confirmed that $\mathrm{AQ}$, like $\mathrm{CQ}$ was a $\mathrm{Hz}$ inhibitor causing a dose related increase in 'free' haem accompanying parasite death (Fig. 9a, b and c). No statistical difference was found in total haem $\mathrm{Fe} /$ trophozoite (fg/cell) between the control and AQ-treated samples (Fig. 9d). This result made it possible to use the percentage values of 'free' haem (Fig. 9a) and $\mathrm{Hz}$ (Fig. 9b) as a direct indication of the effect of AQ on each of the haem species, as was the case for CQ (Figs. 6 and 7). The profiles for the amount of 'free' haem $\mathrm{Fe} /$ trophozoite and $\mathrm{Hz} \mathrm{Fe} /$ trophozoite with increasing AQ concentration (Fig. 9e and f) mirror the profiles obtained with the percentage values of the corresponding haem species (Fig. 9a and b).

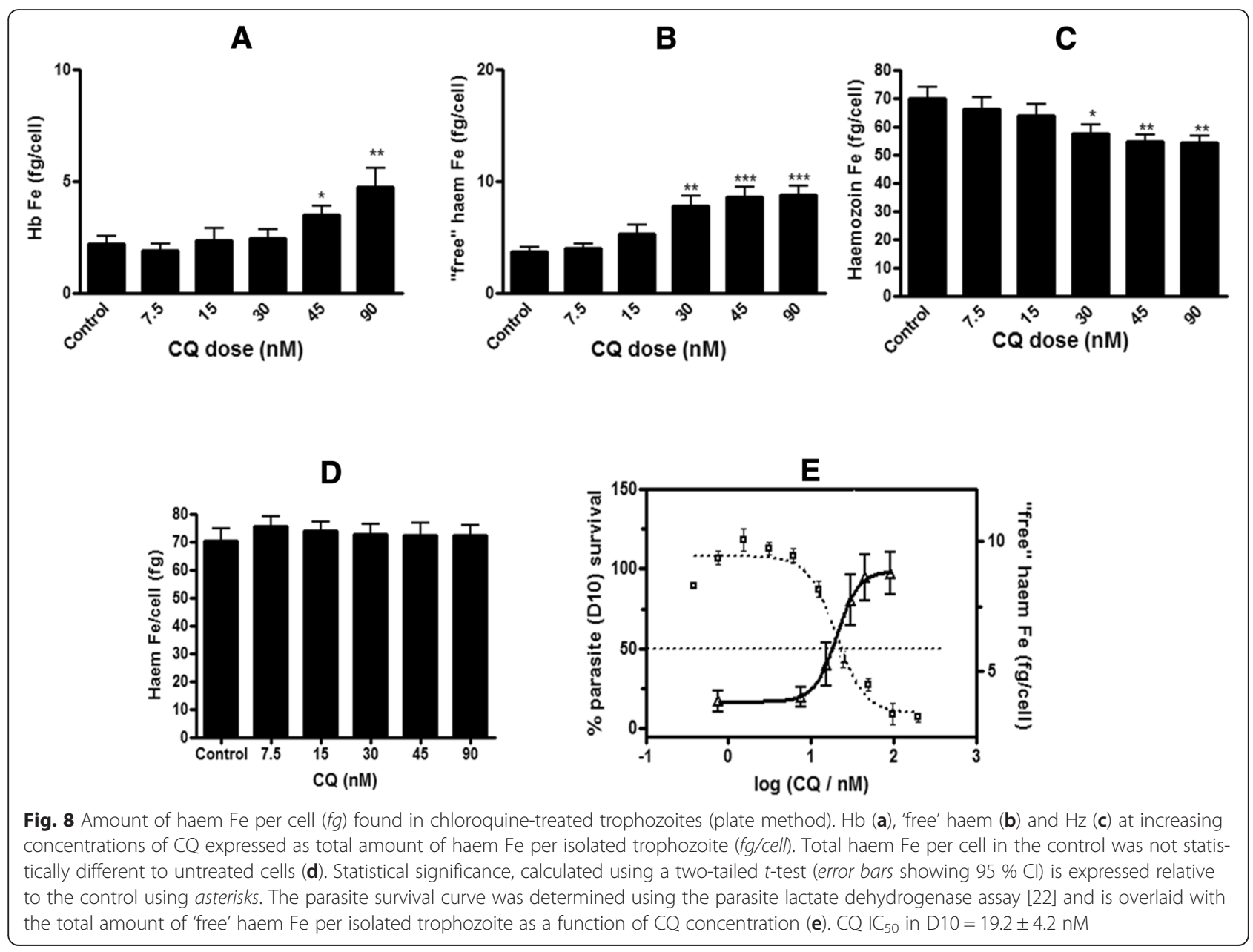




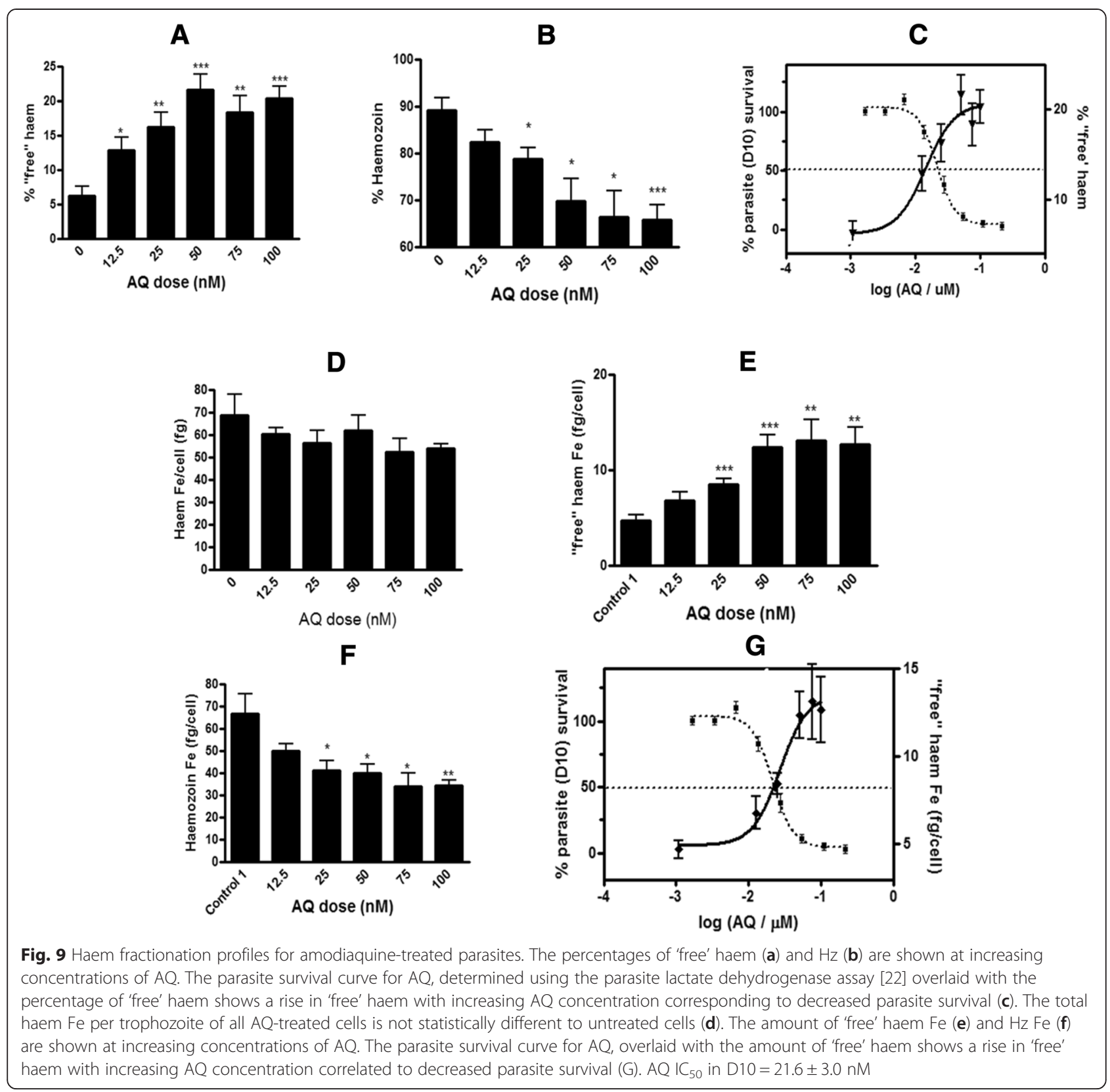

\section{Pyrimethamine}

The plate method was applied to the non-BH inhibiting antifolate PYR [7]. Previously used as a negative control, PYR showed no increase in 'free' haem or decrease in $\mathrm{Hz}$ when tested at $2.5 \times$ its parasite growth inhibition $\mathrm{IC}_{50}$ [12]. At higher concentrations of PYR corresponding to $3.5 \times$ and $4.5 \times \mathrm{IC}_{50}$, the per cent 'free' haem (Fig. 10a) does show a statistically significant increase compared to the control. This increase in 'free' haem is however not dose related and is not accompanied by a decrease in per cent $\mathrm{Hz}$ (Fig. 10b) which remains constant at all PYR concentrations. Furthermore, the increase in the amount of 'free' haem is significant only at the highest dose. These data are consistent with the fact that that PYR is not a $\mathrm{Hz}$ inhibitor.

\section{Atovaquone}

The method was also applied to Atov which shows no $\mathrm{BH}$ inhibition, but has a mechanism of action known to selectively disrupt mitochondrial electron transport in the parasite by inhibiting the cytochrome $b c_{1}$ complex without affecting host cell mitochondria $[25,26]$.

Surprisingly, Atov clearly showed a significant dose dependent increase in percentage 'free' haem and decrease in percentage $\mathrm{Hz}$ (Fig. 11a, b). Although the increase was less than that seen for both CQ and AQ at 


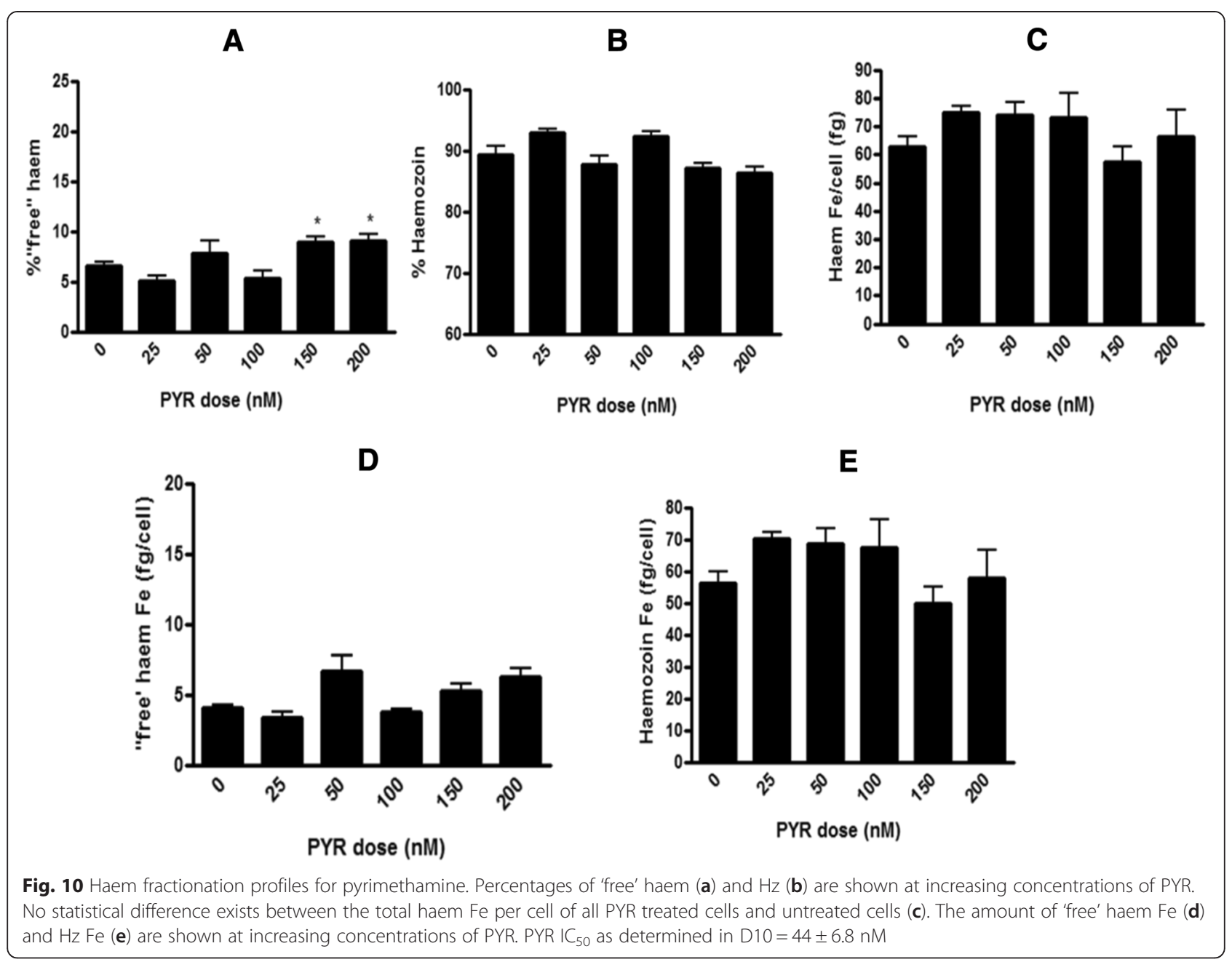

equivalent $\mathrm{IC}_{50}$ values, it was nonetheless significant and dose related. Further investigation however, revealed decreasing total haem Fe per trophozoite in Atov-treated cells, showing that treated cells accumulated less haem than control cells (Fig. 11c). This is in contrast to results obtained for total haem Fe per trophozoite in both CQ (Fig. 7d), AQ (Fig. 9d) and PYR (Fig. 10c) treated cells, where cells treated with drug showed no significant difference to untreated cells. Despite the percentage increase in 'free' haem with increasing Atov concentration, when the amount of 'free' haem Fe per trophozoite (fg/cell) was calculated, it was found to remain constant with increasing dose, with no significant difference to the control (5.4 $\pm 1.6 \mathrm{fg}$ Fe/cell), at the $95 \% \mathrm{CI}$. The decrease in $\mathrm{Hz}$ is likely a result of decreased $\mathrm{Hb}$ uptake and digestion secondary to treatment with this drug. This result does, however, demonstrate the importance of determining the total haem Fe per cell, using cell counts determined with either a haemocytometer or FACS. In the case of Atov, where the total haem Fe in treated cells was significantly less than the control (Fig. 11c), the percentage values for each haem species are misleading (Fig. 11a and b) and the amounts of each haem species per cell (Fig. 11d and e) must be used. This approach demonstrated that there was no change in 'free' haem and no relationship with inhibition of parasite growth (Fig. 11f).

\section{Conclusion}

The successful adaptation of the haem fraction assay from a very low throughput method with high demand on valuable parasite starting material to a more efficient process was achieved and validated using $\mathrm{CQ}$ as a model. The improved throughput plate method is capable of reproducing the results obtained with the flask method using 24 times less starting material and increasing output by at least six-fold. A fluorescent flow cytometry-based technique for the determination of cell counts of isolated trophozoites was also developed. This new method of determining cell counts provided a faster alternative to traditional manual methods of cell 
A

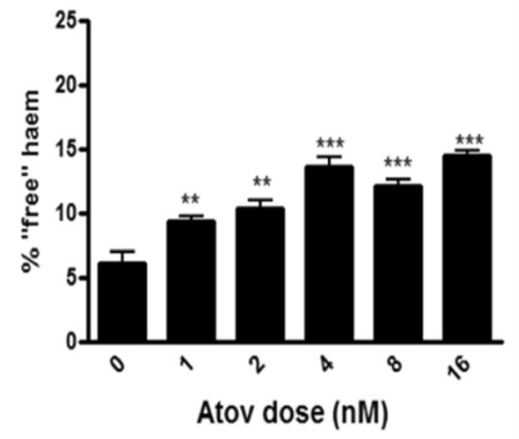

D

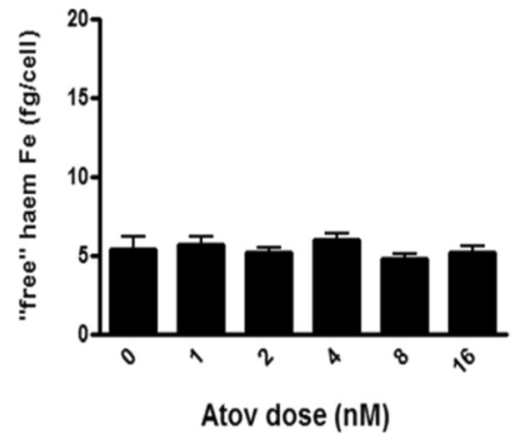

B

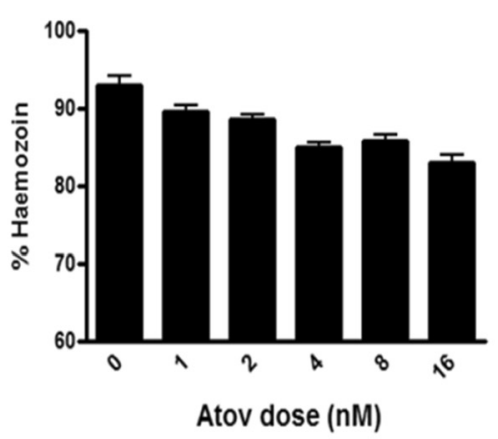

E

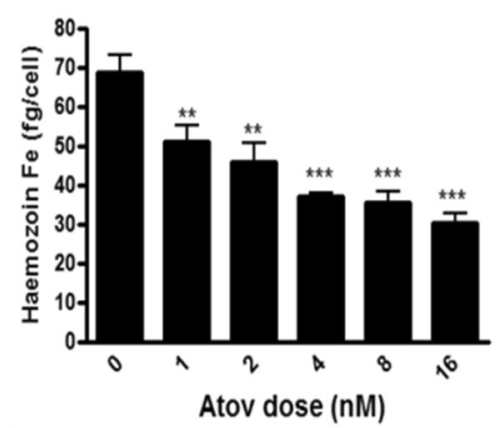

C

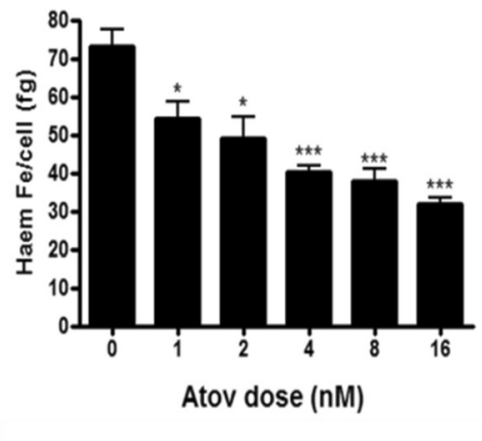

$\mathbf{F}$

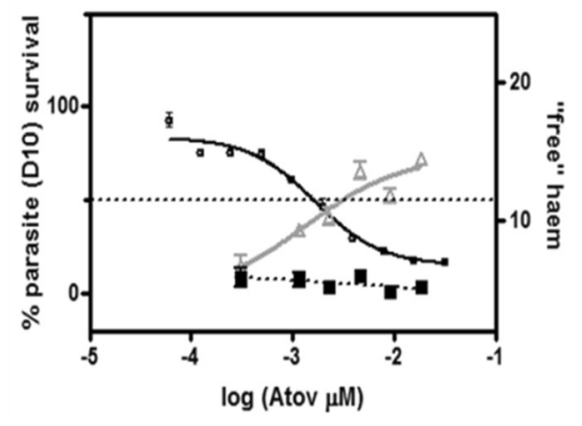

Fig. 11 Haem fractionation profiles for atovaquone. Increase in percentage 'free' haem (a) and decrease in percentage Hz (b) seen with increasing Atov concentration. The total haem Fe $(f g)$ per trophozoite of Atov-treated cells is statistically different to untreated cells (c). Graphs $\mathbf{d}$ and e show the amount of 'free' haem Fe ( $\mathrm{fg} / \mathrm{cel} / \mathrm{l})$ and $\mathrm{Hz}$ Fe per trophozoite respectively with increasing Atov concentration. The parasite survival curve for Atov overlaid with the percentage of 'free' haem (grey graph with open triangles, right axis) shows an apparent rise in 'free' haem with increasing Atov concentration correlated to parasite survival (f). However, by contrast to $\mathrm{Hz}$ inhibitors $\mathrm{CQ}$ and $\mathrm{AQ}$, no relationship in fact exists between parasite survival and the actual amount of 'free' haem Fe (fg/cell) per trophozoite (black dashed graph with closed squares, right axis) which remains constant at $5.4 \pm 0.4 \mathrm{fg}$ haem Fe per cell. Atov $I_{50}$ as determined in $\mathrm{D} 10=2.0 \pm 0.8 \mathrm{nM}$

counting. The plate method was subsequently applied to several other established anti-malarials, providing rapid and valuable insight into mechanistic action of antimalarials and has highlighted the important role which haem plays in the action of several drugs. Results with Atov emphasize the crucial importance of measuring haem levels per cell rather than just percentages of haem species in order to interpret the effects of drugs on parasite haem concentrations. This approach is essential in those cases where the total haem iron per cell changes with drug dose. Applied to novel compounds, this method will provide an important in vitro complement to the existing detergent-mediated $\mathrm{BH}$ inhibition assay in improving understanding of mechanism of action and in exploring structure activity relationships and prospects for rational drug design.

\section{Abbreviations}

CQ: chloroquine; Hz: haemozoin; Hb: haemoglobin; TEM: transmission electron microscopy; EELS: electron energy loss spectroscopy;

$\mathrm{BH}$ : $\beta$-haematin; CQS: chloroquine sensitive strain; DMSO: dimethyl sulfoxide;
PBS: phosphate buffered saline; FACS: flow assisted cell sorting; FSC: forward scatter; SSC: side scatter; AQ: Amodiaquine; Atov: atovaquone;

PYR: pyrimethamine.

\section{Competing interests}

The authors declare they have no competing interests.

\section{Authors' contributions}

JC designed and carried out laboratory experiments, analysed and interpreted data and results and wrote the manuscript. KYF performed experiments on pyrimethamine, analysed the data and reviewed and edited the manuscript. LG assisted in the design and interpretation of all flow cytometry experiments and analysis. PJS co-supervised all the research and reviewed, edited and commented on the manuscript. DWW supervised all research performed by KYF and reviewed, edited and commented on the manuscript. TJE supervised and contributed to all the research, data analysis and interpretation of results, reviewed, edited and commented on the manuscript. All the authors have contributed to, seen and approved the final manuscript.

\section{Acknowledgments}

Research reported in this publication was supported by the National Institute of Allergy and Infectious Diseases of the National Institutes of Health under Award Number R01Al110329. The content is solely the responsibility of the authors and does not necessarily represent the official views of the National Institutes of Health. JMC thanks the National Research Foundation South 
Africa and the University of Cape Town for scholarship support. Original seed funding for this work was provided by the South African Medical Research Council. Tree Star Inc. are thanked for the donation of a one year subscription to FloJo version 10 analysis software. Danni Ramduth from Becton, Dickinson and Company, South Africa is acknowledged for her flow cytometry technical assistance. Dale Taylor is thanked for his help in reviewing and editing parts of this manuscript.

\section{Author details}

'Division of Pharmacology, Department of Medicine, University of Cape Town, Observatory 7925, Cape Town, South Africa. ${ }^{2}$ Department of Chemistry, Vanderbilt University, Station B 351822, Nashville, TN 37235, USA. ${ }^{3}$ Department of Chemistry, University of Cape Town, Private Bag, Rondebosch 7701, South Africa.

Received: 13 March 2015 Accepted: 7 May 2015

Published online: 24 June 2015

\section{References}

1. Francis SE, Sullivan DJ, Goldberg DE. Haemoglobin metabolism in the malaria parasite Plasmodium falciparum. Annu Rev Microbiol. 1997:51:97-123.

2. Egan TJ, Combrinck JM, Egan J, Hearne GR, Marques HM, Ntenteni S, et al. Fate of haem iron in the malaria parasite Plasmodium falciparum. Biochem J. 2002;365:343-7.

3. Ginsburg H, Famin O, Zhang J, Krugliak M. Inhibition of glutathionedependent degradation of heme by chloroquine and amodiaquine as a possible basis for their antimalarial mode of action. Biochem Pharmacol. 1998;56:1305-13.

4. Pisciotta JM, Coppens I, Tripathi AK, Scholl PF, Shuman J, Bajad S, et al. The role of neutral lipid nanospheres in Plasmodium falciparum haem crystallization. Biochem J. 2007:402:197-204.

5. Ambele MA, Egan TJ. Neutral lipids associated with haemozoin mediate efficient and rapid $\beta$-haematin formation at physiological $\mathrm{pH}$, temperature and ionic composition. Malar J. 2012;11:337.

6. Carter MD, Phelan W, Sandlin RD, Bachmann BO, Wright DW. Lipophilic mediated assays for $\beta$-hematin inhibitors. Combinatorial Chem High Througput Scr. 2010;13:285-92.

7. Sandlin RD, Carter MD, Lee PJ, Auschwitz JM, Leed SE, Johnson JD, et al. Use of the NP-40 detergent-mediated assay in discovery of inhibitors of $\beta$-hematin crystallization. Antimicrob Agents Chemother. 2011;55:3363-9.

8. Sandlin RD, Fong KY, Wicht KJ, Carrell HM, Egan TJ, Wright DW. Indentification of $\beta$-hematin inhibitors in a high-throughput screening effort reveals scaffolds with in vitro antimalarial activity. Int J Parasitol Drugs Drug Resist. 2014;4:316-25.

9. Summers RL, Nash MN, Martin RE. Know your enemy: understanding the role of PfCRT in drug resistance could lead to new antimalarial tactics. Cell Mol Life Sci. 2012;69:1967-95.

10. Krogstad DJ, Gluzman IY, Kyle DE, Oduola AMJ, Martin SK, Milhous WK, et al. Efflux of chloroquine from Plasmodium falciparum: mechanism of chloroquine resistance. Science. 1987;238:1283-5.

11. Huy NT, Uyen DT, Maeda A, Trang DTX, Oida T, Harada S, et al. Simple colorimetric inhibition assay of heme crystallization for high throughput screening of antimalarial compounds. Antimicrob Agents Chemother. 2007:51:350-3.

12. Combrinck JM, Mabotha TE, Ncokazi KK, Ambele MA, Taylor D, Smith PJ, et al. Insights into the role of heme in the mechanism of action of antimalarials. ACS Chem Biol. 2013;8:133-7.

13. Ncokazi KK, Egan TJ. A colorimetric high-throughput $\beta$-hematin inhibition screening assay for use in the search for antimalarial compounds. Anal Biochem. 2005;338:306-19.

14. Bei AK, DeSimone TM, Badiane AS, Ahouidi AD, Dieye T, Ndiaye D, et al. A flow cytometry-based assay for measuring invasion of red blood cells by Plasmodium falciparum. Am J Hematol. 2010;85:234-7.

15. Barkan D, Ginsburg H, Golenser J. Optimisation of flow cytometric measurement of parasitaemia in plasmodium-infected mice. Int J Parasitol. 2000;30:649-53.

16. Jun G, Lee J, Jung Y, Park J. Quantitative determination of Plasmodium parasitemia by flow cytometry and microscopy. J Korean Med Sci. 2012;27:1137-42
17. Jiménez-Díaz MB, Mulet T, Gómez V, Viera S, Alvarez A, Garuti H, et al. Quantitative measurement of Plasmodium-infected erythrocytes in murine models of malaria by flow cytometry using bidimensional assessment of SYTO-16 fluorescence. Cytometry A. 2009;75:225-35.

18. Jogdand PS, Singh SK, Christiansen M, Dziegiel MH, Singh S, Theisen M. Flow cytometric readout based on Mitotracker Red CMXRos staining of live asexual blood stage malarial parasites reliably assesses antibody dependent cellular inhibition. Malar J. 2012;11:235

19. Karl S, Wong RP, St Pierre TG, Davis TM. A comparative study of a flow-cytometry-based assessment of in vitro Plasmodium falciparum drug sensitivity. Malar J. 2009;8:294.

20. Zipper H, Brunner H, Bernhagen J, Vitzthum F. Investigations on DNA intercalation and surface binding by SYBR Green I, its structure determination and methodological implications. Nucleic Acids Res. 2004;32, e103.

21. Trager W, Jensen JB. Human malaria parasites in continuous culture. Science. 1976;193:673-5.

22. Makler MT, Ries JM, Williams JA, Bancroft JE, Piper RC, Gibbins BL, et al. Parasite lactate dehydrogenase as an assay for Plasmodium falciparum drug sensitivity. Am J Trop Med Hyg. 1993;48:739-41.

23. GraphPad Prism. 4.0 edition. 10855 Sorrento Valley Rd. \#203, San Diego. CA 92121: GraphPad Software Inc.

24. Altman DG, Bland JM. Measurement in medicine: the analysis of method comparison studies. The Statistician. 1983;32:307-17.

25. Baggish AL, Hill DR. Antiparasitic agent atovaquone. Antimicrob Agents Chemother. 2002;46:1163-73.

26. Srivastava IK, Morrisey JM, Darrouzet E, Daldal F, Vaidya AB. Resistance mutations reveal the atovaquone-binding domain of cytochrome $b$ in malaria parasites. Mol Microbiol. 1999;33:704-11.

\section{Submit your next manuscript to BioMed Central and take full advantage of:}

- Convenient online submission

- Thorough peer review

- No space constraints or color figure charges

- Immediate publication on acceptance

- Inclusion in PubMed, CAS, Scopus and Google Scholar

- Research which is freely available for redistribution 